\title{
ОСОБЕННОСТИ СОСТОЯНИЯ ЭНДОМЕТРИЯ ЖЕНЩИН С БЕСПЛОДИЕМ
}

\author{
Красовская Р.Л., Витязева И.И., Дружинина А.С. \\ ФГБУ «НМИЦ эндокринологии» Минздрава России, \\ Институт репродуктивной медицины, отделение ВРТ
}

\begin{abstract}
АКТУАЛЬНОСТЬ: хронический эндометрит (ХЭ) - клинико-морфологический синдром, характеризующийся комплексом морфофункциональных изменений эндометрия воспалительного генеза, приводящих к нарушению циклической трансформации и рецептивности эндометрия. Проблема своевременной диагностики ХЭ имеет социальное значение, поскольку приводит к нарушению репродуктивной функции, являясь причиной бесплодия, неудачных попыток экстракорпорального оплодотворения, невынашивания беременности, осложненного течения беременности и родов.
\end{abstract}

ЦЕЛЬ: оценить особенности состояния эндометрия у женщин с бесплодием.

МАТЕРИАЛЫ И МЕТОДЫ: проведена оценка клинико-морфологического состояния и рецептивности эндометрия у 362 женщин в возрасте от 24 до 44 лет, обратившимся в отделение ВРТ ФГБУ «НМИЦ эндокринологии» с бесплодием. Пациентки были разделены на две группы в зависимости от наличия или отсутствия признаков ХЭ, выявленных по данным гистологического и иммуноцитохимического (ИЦХ) исследований ткани эндометрия, полученного во вторую фазу менструального цикла на $+5-+7$, что совпадало с предполагаемым «окном имплантации». В группу I включены 265 женщин без морфологических, ИЦХ признаков ХЭ, в группу II - 97 (26,8\%) пациенток с морфологическими и/или ИЦХ признаками ХЭ.

РЕЗУЛЬТАТЫ: длительность бесплодия среди обследуемых женщин составила от 2 до 18 лет, в среднем $5,9 \pm 3,4$ года. Частота ХЭ у женщин с первичным и вторичным бесплодием статистически не различалась $27,3 \%$ и 26,3\% соответственно. Безуспешные попытки ЭКО в анамнезе в группе I имели $86(32,4 \%)$ женщин, во II - 79 (81,4\%), в среднем 3,1 попытки на каждую женщину из группы II. В структуре гинекологических заболеваний частота трубно-перитонеального фактора (ТПФ) составила $24,1 \%$ (n - 64) в группе I и 59,8\% (n - 58) в группе II; гиперпластических процессов эндометрия в анамнезе - 12,4\% (n - 33) и 38,1\% (n - 37); ранее выявленного ХЭ - 15,4\% (n - 41) и 34,1\% (n -33) соответственно. По данным бактериологического исследования микробиоты полости матки у пациенток группы I в 78,9\% (n - 209) преобладала лактобациллярная микрофлора (ЛБМ); в группе II в 59,8\% (n - 58) отмечено снижение титра ЛБМ, в 30,9\% (n - 30) рост аэробно-анаэробной флоры, в 9,3\% (n - 9) - условно-патогенной микрофлоры (УПМ), в 4,1\% (n - 4) отмечен рост грибов рода Candida и инфекций, передаваемых половым путем. По данным ИЦХ исследования эндометрия у пациенток из группы I нарушение рецепторного статуса эндометрия отмечено в $9,1 \%$ (n - 24), преимущественно в сторону снижения рецепторов прогестерона; в группе II в 36,1\% (n - 35) в сторону снижения уровня рецепторов эстрогенов.

ВЫВОДЫ: распространенность ХЭ у женщин с бесплодием составила 26,8\%, без статистической разницы между пациентками с первичным и вторичным бесплодием. Ведущая роль в структуре гинекологической патологии отводится ТПФ, который у женщин с ХЭ встречается в два раза чаще. По данным бактериологического исследования микробиоты полости матки у женщин с ХЭ обнаруживается снижение титра ЛБМ и контаминация УПМ. В развитии нарушений имплантации эмбрионов при ХЭ имеет место рецептивный дисбаланс эндометрия за счет нарушения индекса соотношения рецепторов эстрогенов и прогестерона, преимущественно за счет снижения экспрессии рецепторов эстрогенов. 